\title{
Plasma cell dyscrasia with polyneuritis and dermato-endocrine alterations. Report of a new case outside Japan
}

\author{
M. S. MOYA-MIR \\ M.D. \\ R. BARBADILLO \\ M.D. \\ T. MARTin-Jimenez \\ M.D.
}

\author{
F. MARTIN-Martin \\ M.D. \\ V. Cuervas-Mons \\ M.D.
}

I. SANCHEZ-MiRO

M.D.

\section{J. A. Garcia-Merino \\ M.D .}

\begin{abstract}
Internal Medicine Department, Clinica Puerta de Hierro, Medical School of The Universidad Autónoma de Madrid, Madrid, Spain
\end{abstract}

\begin{abstract}
Summary
A new syndrome has been described comprising polyneuropathy, oedema, hyperpigmentation and thickening of the skin, gynaecomastia in males and amenorrhoea in females, monoclonal gammopathy, papilloedema and diabetes. There is frequent osteosclerosis with or without plasmacytoma, hepatosplenomegaly and polycythaemia. There is a good response to corticosteroids, immunosuppressive drugs and occasionally to excision or irradiation of the plasmacytoma. This syndrome was first described in Japan, and is still seen predominantly there, and only occasionally in other areas. An example in a 51-year-old Spanish female is described: she had a spectacular response to prednisone and melphalan. The aetiopathogenic possibilities are discussed.
\end{abstract}

\section{Introduction}

Iwashita, Inoue and Nagamatsu (1971) first described a patient with monoclonal IgG-lambda gammapothy, polyneuritis, skin hyperpigmentation, hyperhidrosis, hypertrichosis and subclinical diabetes, in whom the post-mortem study failed to demonstrate the existence of solitary plasmacytoma, multiple myeloma, collagenosis, amyloidosis or malignancy. Other cases have been described since, with very similar characteristics (Imawari et al., 1974; Akihama, Miura and Shibata, 1975; Saikawa, Nagamatsu and Igata, 1975; Amiel, Machover and Droz, 1975; Trentham, Masi and Marker, 1976; Iwashita, 1976; Lièvre, 1977; Meshkinpour, Myune and Kramer, 1977). In another group with a similar clinical picture (Scheinker, 1938; Crow, 1956; Gupta and Prabhakar, 1965; Shimpo, 1968; Shimomori and Kusumoto, 1970; Yodoi, Takatsuki and Wakisaka, 1973; Shimizu, 1974; Nishitani, Noguchi and Fukase, 1975; Iwashita et al., 1977; Waldenström et al., 1978), there is either a solitary plasmacytoma or an atypical myeloma, the most unusual feature being osteosclerosis. Most of the patients have been Japanese, although cases have been observed in Austria (Scheiker, 1938), England (Crow, 1956), India (Gupta and Prabhakar, 1965), North-America (Trentham et al., 1976; Meshkinpour et al., 1977), France (Amiel et al., 1975; Lièvre, 1977) and Sweden (Waldström et al., 1978). This communication presents one patient with all the features of the syndrome which has lately been designated as 'plasma cell dyscrasia with polyneuritis and multiple dermic and endocrine alterations', or 'multisystemic syndrome of unknown origin' (Meshkinpour et al., 1977).

\section{Case report}

A 51-year-old Spanish woman was first seen in June 1977, complaining of progressive dyspnoea and loss of strength. Since a very early age she had had Raynaud's phenomenon in both hands. She was amenorrhoeic since 1971. In 1972 she first observed cold-related facial flush, asthenia, a feeling of heaviness and paraesthesiae in the lower limbs, and malleolar oedema. In February 1975, progressive 
dyspnoea and slight hyperthermia appeared. One year later there was a progressive increase of the paraesthesiae and loss of strength in the lower limbs, dysaesthesia and loss of sensation, mainly distal in distribution. At the same time she observed hypertrichosis and thickening of the skin of the limbs, but not of the face. In May 1976, she observed loss of strength with distal distribution in both upper limbs.

Clinical examination On admission the patient presented general hyperpigmentation, with erythematous scaly skin mainly in the lower limbs. There were vascular spiders in the lower third of the left leg (Fig. 1), malar telangiecstasia, clubbing of the fingers and palmar retraction. There was no lymphadenopathy. There were crepitant rales in the left basal lung area. The liver was palpable $4 \mathrm{~cm}$ below the right and the spleen $3 \mathrm{~cm}$ below the left costal margin. There was no ascites. There was slight malleolar oedema, and bilateral papilloedema. The power in the distal muscle groups of the upper limbs was reduced, and even more so in the lower limbs, with distal amyotrophia. There was bilateral loss of the tricipital, patellar and ankle jerks and loss of pain sensation in a stocking distribution. Gait was difficult, with steppage. There was no discernible thickening of the peripheral nerves. The rest of the clinical examination was normal.

Laboratory tests were as follows: leucocytes, $5.6 \times 10^{9} / 1$; platelets, $491 \times 10^{9} / 1 ; \mathrm{Hb}, 12.4 \mathrm{~g} / \mathrm{dl}$; ESR, $25 \mathrm{~mm} / \mathrm{hr}$. SGOT, SGPT, CPK, LDH, aldolase, alkaline phosphatase, bilirubin, cholesterol, uric acid, BUN, glucose and electrolytes were all within the normal range. Oral glucose tolerance test: basal, $3.9 \mathrm{mmol} / \mathrm{l} ; 30 \mathrm{~min}, 6.6 ; 60 \mathrm{~min}, 6.3$; $120 \mathrm{~min}, 6 \mathrm{mmol} / \mathrm{l}$. Hormonal determinations: LH 22 u./l; FSH 43 u./l; oestrogens, <36 pmol/l; progesterone, $0.38 \mathrm{nmol} / 1$; testosterone, $1.4 \mathrm{nmol} / 1$; $T_{4}, 64 \mathrm{nmol} / 1$ and $T_{3}, 1.6 \mathrm{nmol} / \mathrm{l}$. The urinalysis showed leucocytes and protein $180000 / \mathrm{min}(0 \cdot 143$ $\mathrm{g} / 24 \mathrm{hr}$ ). Porphyrins, 5-hydroxy-indole-acetic acid and glucose were negative.

The agglutination tests for Salmonella typhi, $S$. paratyphi and Brucella were negative, as also was an antiglobulin test for Brucella. The Mantoux test with $1: 10000$ PPD, Wassermann, and VDRL tests, the urine culture and examination with ZiehlNeelsen stain were all negative.

Also negative were the following determinations: tests for $\mathrm{HB}_{\mathrm{s}} \mathrm{Ag}$, anti-nuclear, anti-mitochondrial and anti-smooth muscle antibodies, cryoglobulins and Singer-Plötz test. The plasma proteins were: albumin $41.0 \mathrm{~g} / 1 ; \alpha_{1}$-globulin, $3.0 \mathrm{~g} / \mathrm{l} ; \alpha_{2}$-globulin, $6.0 \mathrm{~g} / \mathrm{l} ; \beta$-globulin, $10.0 \mathrm{~g} / \mathrm{l} ; \gamma$-globulin, $23.0 \mathrm{~g} / \mathrm{l}$. Immunoglobulin quantification: IgG, 22.3 g/l (normal range 8-18), IgA, $2 \cdot 45 \mathrm{~g} / 1(0 \cdot 9-4 \cdot 5)$; IgM, $1.25 \mathrm{~g} / \mathrm{l}(0 \cdot 6-2 \cdot 5)$. Immunoelectrophoretic study against anti-IgG, anti-IgA, anti-IgM, anti-kappa and anti-lambda light chains demonstrated both inz plasma and in urine an IgG-lambda para $\frac{\mathbb{D}}{2}$ protein.

The bone marrow study was reported as normal, with $1 \%$ plasma cells.

The X-rays disclosed only right pleural effusion, dorso-lumbar spondilo-arthrosis and vascular cal 흠 cification in the pelvic area. A barium-meal was? normal. There were no osteolytic or sclerotic foci. $\stackrel{\square}{\square}$

A liver scan showed 'non-specific hepatospleno-๘" megaly'.

Rectal mucosal and hepatic biopsy samples were normal. There were no deposits of amyloid material. $\vec{\omega}$ The skin biopsy study yielded only collagenization of the dermis, and the muscle biopsy showed signso of muscle atrophy only.

Lumbar puncture showed a clear CSF containing $0.53 \mathrm{~g} / \mathrm{l}$ protein but was otherwise normal. CSF' protein electrophoresis, performed after institutiono of treatment, showed increased $\gamma$-globulin.

Nerve-conduction studies were performed. The distal latencies were increased and the evoked? muscle-action potentials were polyphasic and of reduced amplitude. The motor conduction velocities ranged between $24 \mathrm{~m} / \mathrm{sec}$ in the right peroneal nerve $\mathrm{D}$

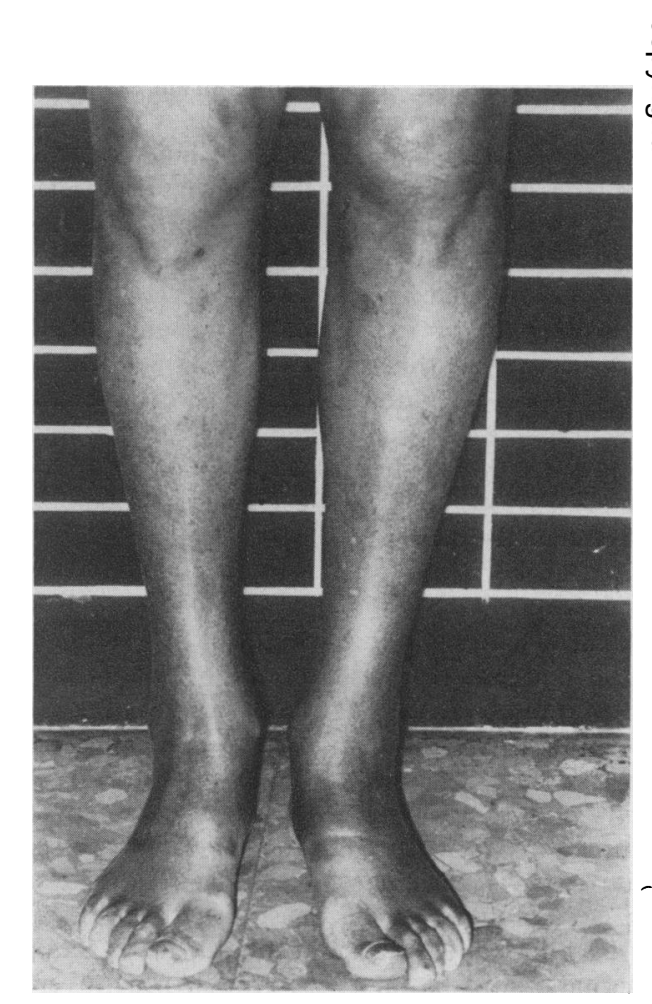

FIG. 1. Hyperpigmentation and atrophic skin with venous dilatation in the lower limbs. 
and $49 \mathrm{~m} / \mathrm{sec}$ in the left ulnar nerve. Sensory potentials were unrecordable. The electromyographic examination showed distally many fibrillations and positive sharp waves.

In the 3 months following this first study, the polyneuropathy worsened to a point preventing walking, ankle oedema increased and ascites appeared. Treatment was then instituted with melphalan $2 \mathrm{mg} / 24 \mathrm{hr}$ and prednisone $40 \mathrm{mg} / 24 \mathrm{hr}$, and within one week a spectacular improvement was achieved, oedema, ascites and pleural effusion disappeared, skin thickening and hyperpigmentation diminished and the polyneuropathy symptoms showed a definite improvement. The prednisone dosage was reduced 15 days later to $20 \mathrm{mg} / 24 \mathrm{hr}$ and, 45 days after institution of treatment, the patient had resumed normal life and activities and was asymptomatic but for a slight diminution of the strength and sensibility in the lower limbs. The paraprotein was no longer demonstrable in plasma

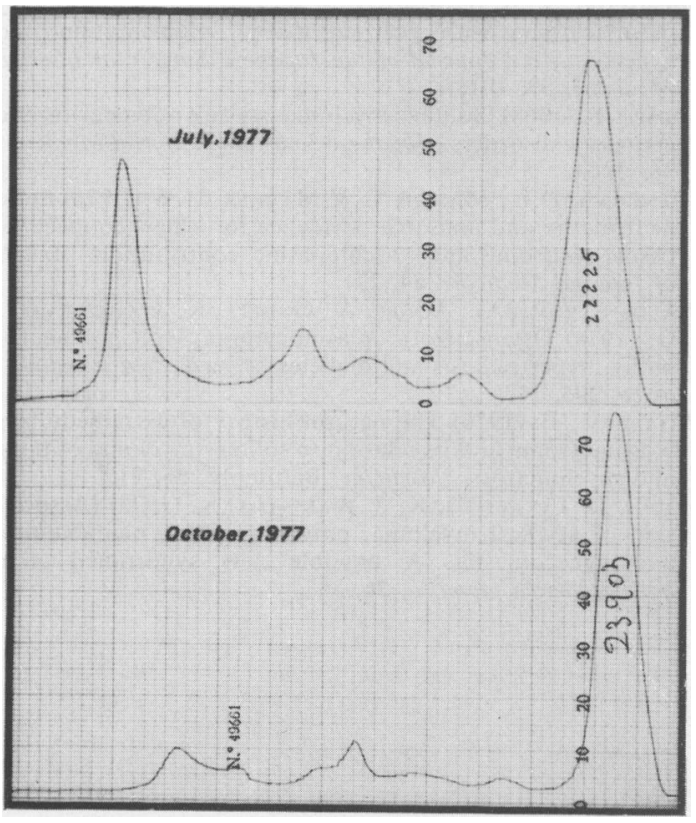

FIG. 2. Plasma protein electrophoresis before and after treatment with prednisone and melphalan. The narrowbased peak, formerly evident in the $\gamma$-globulin region has disappeared.

or urine (Fig. 2). Eight months after starting treatment (June 1978) the administration of melphalan was interrupted because of leucopenia. The improvement has persisted up to the last follow-up visit (May 1979).

\section{Discussion}

The actual nature of the syndrome is as yet unknown. Twashita (1976) classifies it into either cases with or cases without myeloma. There are several aetiopathogenic possibilities that would seem probable:

(a) Development of a paraprotein which in its turn would give rise to the different manifestations. This possibility is supported by the absence of other pathology which might explain variable features of the cases (Iwashita et al., 1971; Akihama et al., 1975; Saikawa et al., 1975; Amiel, et al., 1975; Iwashita, 1976; Lièvre, 1977). Against this possibility is the existence of cases without paraprotein, but with hypergammaglobulinaemia (Imawari et al., 1974; Trentham et al., 1976; Meshkinpour et al., 1977; Scheinker, 1938; Crow, 1956; Gupta and Prabhakar, 1965; Shimomori and Kusumoto, 1970). However, as benign monoclonal gammopathy is relatively frequent, one would expect a more frequent presentation of this syndrome and, finally, there are only rare cases of polyneuropathy ascribed to 'benign' paraproteinaemia (Read, Vanhegan and Matthews, 1978).

(b) Vasculitis, as in the cases of Trentham et al. (1976), and Amiel et al. (1975), which would suggest a connective tissue disease. The presence of Raynaud's phenomenon in the present case and dysphagia in another (Trentham et al., 1976) would make this syndrome resemble scleroderma. Furthermore, the lesions improve with corticosteroids.

(c) Initial stages of multiple myeloma. The evolution of solitary plasmacytoma to multiple myeloma is well known (Wiltshaw, 1976). The syndrome might be an intermediate stage between both extremes, at least in the cases where plasmacytomas have been demonstrated. This 'myeloma', however, is most peculiar: it is in all cases osteosclerotic, save perhaps for the case of Gupta and Prabhakar (1965).

(d) Storage disease with deposition of some material as yet undetected.

(e) Auto-immune disease different from vasculitides which, as in possibility (a), might have racial and/or environmental factors contributing to its development.

Whatever the cause or mechanism may be, all cases are not older than 52 years, there is hyperpigmentation and/or thickening of the skin, there is polyneuropathy, oedema and gynaecomastia in males and amenorrhoea in females. In $>50 \%$ of the cases there is an IgG-lambda paraproteinaemia, plasmacytoma, osteosclerosis, limb hirsutism, hyperhidrosis, hepatomegaly and/or solenomegaly, papilloedema, diabetes and increased CSF protein. Frequently there is polycythaemia and endocrine alterations other than those already described. 
All these features were seen in the present case, in whom solitary plasmacytoma, multiple myeloma, amyloidosis, tuberculosis, collagen disease and malignant disease were ruled out with reasonable certainty, and which improved spectacularly, even to the disappearance of the paraprotein, upon treatment with prednisone and melphalan. In the cases previously published, improvement has been observed with corticosteroids, melphalan, cyclophosphamide, excision of the plasmacytoma and irradiation of the plasmacytoma.

\section{Acknowledgments}

The authors are grateful to The Japanese Association on Medical Sciences, Japanese Medical Association, and Tokyo Medical College Library, for referring photocopies of Japanese publications.

\section{References}

Akihama, T., Miura, A. \& Shibata, A. (1975) [A case of plasma cell dyscrasia associated with polyneuropathy and hormonal disturbance]. Clinical Haematology. Tokyo, 16, 749.

Amiel, J.L., Machover, D. \& Droz, J.P. (1975) Dyscrasie plasmocytaire avec artériopathie, polyneuropathie et syndrome endocrien. Une maladie japonaise chez un italien. Annales de médecine interne, 126, 745.

Crow, R.S. (1956) Peripheral neuritis in myelomatosis. British Medical Journal, 2, 802.

Gupta, S.P. \& Prabhakar, B.R. (1965) Peripheral neuropathy in solitary myeloma. British Medical Journal, 2, 1004.

Imawari, M., Akatsuka, N., Ishibashi, M., BepPU, H., Suzuki, H. \& Yoshitoshi, Y. (1974) Syndrome of plasma cell dyscrasia, polyneuropathy, and endocrine disturbances. Report of al case. Annals of Internal Medicine, 81, 490.

IWASHITA, H. (1976) [Polyneuropathy associated with dermato-endocrinological changes and dysglobulinaemia.] Advances in Neurological Sciences. Tokyo, 20, 709.

Iwashita, H., Inoue, N. \& Nagamatsu, K. (1971) [Polyneuropathy, pigmentation, diabetes mellitus and monoclonal gammopathy. Report of an autopsy case.] Clinical Neurology. Tokyo, 11, 492.

Iwashita, H., Ohnishi, A., Asada, M., Kanazawa, Y. \&
Kuroiwa, Y. (1977) Polyneuropathy, skin hyperpigmenta:๊ tion, edema and hypertrichosis in localized osteosclerotic myeloma. Neurology. Minneapolis, 27, 675.

LiÈVRE, J.A. (1977) Dyscrasie plasmocytaire avec poly- 은 neuropathie et troubles endocriniens. Annales de médecine interne, 128, 561.

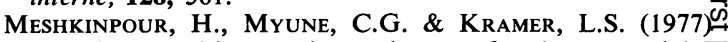
A unique multi-systemic syndrome of unknown origin. Archives of Internal Medicine, 137, 1719.

Nishitani, H., Noguchi, S. \& Fukase, M. (1975) [Immuno $\overline{\bar{n}}$ globulin and neuropathy: Myelomatous polyneuropathy associated with pigmentation.] Neurological Medicine.@ Tokyo, 2, 325.

Read, J., Vanhegan, R.I. \& Matthews, W.B. (1978) Peripheral neuropathy and benign IgG paraproteinaemia. $\vec{O}$ Journal of Neurology, Neurosurgery and Psychiatry, 41, 215.-

Saikawa, S., Nagamatsu, K. \& Igata, A. (1975). [Poly $\vec{\omega}$ neuropathy with monoclonal gammopathy, papilloedema skin pigmentation and diabetes mellitus.] Neurologicap Medicine. Tokyo, 2, 384.

SCHEINKER, I. (1938) Myelom und Nervensystem: Über eine bisher nicht beschriebene mit eingentümlichen Hautver-g anderungen einhergehende Polyneuritis bei sinem plasma-o zellulären Myelom des Sternums. Deutsche Zeitschrift fürg Nervenheilkunde, 147, 247.

SHimizu, T. (1974) [Myeloma and nervous system.] Naika 34, 188.

Shimomori, T. \& Kusumoto, M. (1970) [A case of solitary을 plasmacytoma with polyneuropathy, pigmentation andgynecomastia.] Journal of the Japanese Society of Internat Medicine, 59, 1018.

SHImPO, S. (1968) [Solitary myeloma causing polyneuritis and endocrine disorders.] Japanese Journal of Clinical Medicinge $\overrightarrow{0}$ 26, 2444.

Trentham, D.E., Masi, A.T. \& Marker, H.W. (1976) PQ neuropathy and anasarca. Evidence for a new connectidetissue syndrome and vasculopathic contribution. Anngls of Internal Medicine, 84, 271.

Waldenström, J.G., Adner, A., Gydell, K. \& Zettervallo O. (1978) Osteosclerotic 'plasmocytoma' with polyneuropathy, hypertrichosis and diabetes. Acta medica scandinavica, 203, 297.

Wiltshaw, E. (1976) The natural history of extramedullaryo plasmacytoma and its relation to solitary myeloma of bones and myelomatosis. Medicine. Baltimore, 55, 217.

Yodd, J., TAKatsuki, K. \& Wakisaka, K. (1973) [Associaz tion of atypical myeloma, polyneuropathy, pigmentation and gynecomastia. A possible new syndrome.] Act haematologica japonica, 36, 363. 